\title{
COMMUNICATION STYLE: THE MANY SHADES OF GRAY
}

\author{
Shulamith Kreitler \\ School of Psychological Sciences, Tel-Aviv University (Israel)
}

\begin{abstract}
The major aspects of communication include the communicating individual, the addressee, and the style of communication which can be more objective or subjective. The present study examines the role of the communicator's motivation and the identity of the addressee of the communication in regard to the style of communication. The motivation was assessed in terms of the cognitive orientation approach (Kreitler \& Kreitler) which assumes that motivation is a function of beliefs that may not be completely conscious. The motivation to communicate may be oriented towards sharing and self disclosure or towards withdrawal and distancing oneself from others. The style of communication was assessed in terms of the Kreitler meaning system which enables characterizing the degree to which the communication is based on means that are more objective and interpersonally-shared means (viz. attributive and comparative means) or more personal-subjective ones (viz. examples and metaphors). The hypothesis was that the style of communication is determined by one's motivation and by the recipient's characteristics, which in the present context was gender. It was expected that when the motivation supports sharing and the addressee is a woman the style would be mainly subjective, while when the motivation supports withholding information and the addressee is a man the style would be objective. The participants were 70 undergraduates. The tool was a cognitive orientation questionnaire. The experimental task was a story that had to be recounted. The narratives were coded in terms of the Kreitler meaning system. The data was analyzed by the Cox proportional hazards model. The findings supported the hypothesis of the study. Major conclusions referred to the motivational determinants of communication styles.
\end{abstract}

Keywords: Communication, style, sharing, motivation, cognitive orientation.

\section{Introduction}

Communication is a complex multi-functional process used in different contexts for an ever-increasing number of goals. The major aspects of communication include the communicating individual, the recipient of the communication, the contents of the communication and the style of communication (Barnlund, 2008; Littlejhohn, Foss, \& Oetzel, 2021). The interplay between the three mentioned factors turns communication into a dynamic complex which is almost continually changing. Within this complex, it may be possible to focus on one or another of the components in order to assess its relative contribution to the total effect in the final stage.

Communication styles have a strong impact on the outcomes of the act of communication. However, communication styles are not universal but are rather adapted to different contexts. For example, there are different communication styles in romantic relations and in the workplace (Kuria, 2019; Wegner, Roy, Gorman, \& Ferguson, 2018). The communication styles dealt with in the present study were those characterizing social relations between acquaintances. These were the styles of sharing information or withholding it. These styles were identified by interviewing subjects about the goals of communication in neutral social contexts (see Kreitler, 2021, chapter 17).

Style is however a characteristic of the communication itself. The determinants of style reside in the communicator and in the addressee. In regard to the communicator, we focused on his or her motivation to communicate in the shared or withdrawal kind of style. The communicator's motivation was conceptualized and assessed in the framework of the cognitive orientation (CO) theory (Kreitler, 2004, 2014b; Kreitler \& Kreitler, 1982), which assumes that motivation is a function of beliefs that may not be completely conscious and may differ from one's conscious intention. According to the CO approach, behavior is a function of a motivational disposition which is implemented by a behavioral program. The motivational disposition is a vector defined by four belief types: about oneself (i.e., one's habits, feelings), general beliefs about others and reality, beliefs about rules and norms (i.e., how thing 
should be), and beliefs about goals and wishes (i.e., how one would like things to be). The four belief types do not refer directly to the behavior in question but to its underlying meanings which are identified by a systematic standard stepwise interviewing with pretest subjects. A previous study supported the validity of the described procedure for predicting expressive communicability in schizophrenics and healthy individuals (Kreitler, Schwartz, \& Kreitler, 1987).

The major characteristic of the addressee that was studied was gender. The assumption was that the communicator's style of communication is affected to an appreciable extent by the gender of the addressee (e.g., Almushayqih, 2020).

The style of the communication was conceptualized and assessed in terms of the meaning system (Kreitler, 2014a, 2021; Kreitler \& Kreitler, 1990) which enables characterizing narratives with respect to the meaning dimensions (i.e., contents, such as location. emotions), the types of expression (e.g., examples, comparisons), the forms of expression (e.g., positive or negative), and referent shifts (e.g., staying around the initial input or not). Types of relation are the major feature that distinguishes between objective interpersonally-shared communications and personal-subjective communications. The former include expressions in the form of propositions describing qualities or actions, and comparisons including descriptions of similarities, differences, relationalities and complementary relations. In contrast, persona-subjective types of relation include exemplifying-illustrative description of examples, situations or scenes, as well as interpretational, metaphoric (conventional or innovative) and symbolic. These differences are based on studies in which subjects were requested to communicate interpersonal or personal communications (Kreitler \& Kreitler, 1990).

\section{Objectives}

The present study examines the role of the communicator's motivation and the identity of the recipient of the communication in regard to the style of communication.

The hypothesis was that the style of communication is determined by one's motivation and by the recipient's characteristics, which in the present context was gender. The major expectation was that when the $\mathrm{CO}$ of motivation orients towards sharing and the addressee is a woman the communication style would be subjective-personal, while when the $\mathrm{CO}$ motivation orients towards withholding and the addressee is a man the communication style would be interpersonal-objective.

\section{Method}

\subsection{Method: Participants}

The subjects were 70 undergraduates in the behavioral sciences, including an equal number of men and women.

\subsection{Method: Design}

The design of the study was a two factor design. One factor was the CO motivation of the communicator: sharing versus withdrawing, whereas the second factor was the gender of the address: male versus female.

\subsection{Method: The experimental task}

The communication referred to the description of a weekend excursion by a family of four in the course of which the 4-year old child fell and was badly hurt. The experimental task was to communicate the story to a hypothetical male or female.

\subsection{Method: Tools}

The motivation was assessed in terms of the CO approach (Kreitler \& Kreitler, 1982) which assumes that motivation is a function of beliefs which may orient towards sharing and self disclosure or towards withdrawal and distancing oneself from others. The CO-based motivation was assessed by means of a $\mathrm{CO}$ questionnaire which included 40 statements: 10 for beliefs about self, 10 for general belief, 10 for norm beliefs and 10 for goal beliefs. Responses were to be given by checking one of four presented alternatives, ranging from Very true to Not true at all, scored as 4 to 1 . In each belief type half of the items oriented towards withholding and half towards sharing. The subject got for each belief type only one score that represented the summed directions of the two kinds. The contents of the beliefs represented themes supporting sharing (e.g., expressing one's feelings has a relaxing effect, disclosing one's attitudes is important for making friends) or withholding information (e.g., trusting others may be dangerous, it is never helpful to let others know your real thoughts). Each subject got four scores: one for beliefs about 
self, one for general beliefs, one for norm beliefs and one for goal beliefs. The reliabilities of each of the four scores in terms of alpha Cronbach ranged from .79 to .85. (Kreitler, 2021, chapter 17)

The style of communication was assessed in terms of the Kreitler meaning system which enables characterizing the degree to which the communication is based ontypes of relation characterizing the objective interpersonal-shared mode of communication or the personal-subjective one. The style of communication was based on scoring the narrative based on the experimental task (see 3.2). The following six types of relation define the objective interpersonal mode of communicating: attribute-describing qualities (e.g., he is a nice person), attibutive describing actions (e.g., she helps others), comparative-similarity (e.g., love is like happiness), comparative-difference (e.g., helping differs from punishing), comparative-relational (e.g., a scratch is less than a wound), comparative-complementary (e.g., crying weakens through being comforted). The following six types of relation define the subjective personal mode of communicating: exemplifying instance (e.g., boy is for example a four-year old), exemplifying situation (e.g., pain - a person bent over with pain), exemplifying-scene (e.g., when you fall everyone comes to you to help you get up and the ask you how they can help), metaphoric-interpretation (e.g., pain is the unavoidable lesson of life), metaphor-conventional (e.g., to be happy is like being in the seventh heaven), metaphor-original (e.g., joy is like swimming in sweet light), metaphor-symbolic (e.g., love is like a beautiful flower with golden petals covering painful thorns). Each narrative of the task got first two scores: one for the number of types of relation of the objective style and one for the number of types of relation of the subjective style. Since in the beginning most subjects used a mixture of both kinds of styles, the major dependent variable of the study was defined as the time (in seconds) it took the subject to settle on the style which consisted in at least $75 \%$ of one style (i.e., either objective or subjective). (For the inter-rater reliability see Procedure).

\subsection{Method: Procedure}

Each subject related the story only once - to a female or a male. The recorded stories were analyzed by two independent judges in terms of the style of communicating. In cases in which differences in ratings between any two judges exceeded two points, a discussion between the raters was used for deciding on a concordant rating. Thus, the degree of correspondence between the two ratings for all recorded stories was high (see Tools). The mean correlation between two independent raters was .70.

\section{Results}

The data was analyzed by the Cox proportional-hazards model which is a regression model enabling studying the association between several predictor variables and the time it takes for a phenomenon to occur. In the present study the predictor variables were the scores in the four types of beliefs and the gender of the addressee. The dependent variable was the time it took for the subject in the study to get to the point of $75 \%$ of types of relation of one of the styles of communicating. It was expected that the subject whose $\mathrm{CO}$ scores indicate the motivation for sharing would settle sooner on the style of sharing, while the subject whose $\mathrm{CO}$ scores indicate the motivation for withholding would settle sooner on the style of withholding. The manifestation of the styles was expected to correspond also to the gender of the addressee.

The findings in Table 1 show that the following three predictors had significant contributions: beliefs about norms, beliefs about self and general beliefs. The highest contribution was by beliefs about self. The contribution of beliefs about goals was not significant. The effect of the gender of the addressee was significant. The whole model was found to be significant.

Table 1. Results of Cox proportional hazards model with motivation for communication and gender of the addressee as predictors and style of communication as dependent variable.

\begin{tabular}{|l|r|r|r|r|}
\hline Predictors & B & SE & Wald & Sig \\
\hline Motivation: norms & -.974 & .397 & 6.142 & .013 \\
\hline Motivation: beliefs about self & -2.199 & .414 & 31.311 & .000 \\
\hline Motivation: goals & -.096 & .224 & .147 & .681 \\
\hline Motivation: general beliefs & -.918 & .398 & 5.321 & .021 \\
\hline Gender of addressee & .522 & .219 & 5.608 & .030 \\
\hline
\end{tabular}

Chi-square $=8.664, \mathrm{df}=4 / 1, \mathrm{p}=.018$ 


\section{Discussion}

The results showed that the belief types of the $\mathrm{CO}$ motivation for communication and the addressee's gender accounted for the communication style applied by the communicator. When the CO of motivation supported withholding and the addressee was a man the communication style was mainly of the objective kind, and when the $\mathrm{CO}$ of motivation supported sharing and the addressee was a woman, the communication style was mainly of the subjective kind. Other cases were matched by communication styles of mixed kinds, manifesting the different shades of gray.

The fact that only three belief types had significant contributions does not disconfirm the major tenet of the $\mathrm{CO}$ theory, according to which the support of only three belief types suffices for shaping a course of behavior (Kreitler \& Kreitler, 1982).

Thus, the findings support the hypothesis about the role of $\mathrm{CO}$ predictors in regard to communication style. Also, the expected role of the gender of the addressee has been confirmed. However, it seems that that the gender of the addressee fulfills in this context a relatively less significant role than the $\mathrm{CO}$ belief types.

Of the four belief types the most significant role in the prediction was played by the beliefs about oneself followed by beliefs about norms. The former reflect primarily the self-image, the latter one's norms in regard to communication in general and possibly in regard to the proper behavior in regard to the addressee. General beliefs fulfill in this context a relatively less important role.

\section{Conclusions}

The conclusion of the study is that style of communication is affected by the communicator's motivation. The findings show that applying objective and subjective communication styles is a function of one's beliefs about issues that do not refer directly to communication in general or degree of disclosure or withdrawal of information but only to the meanings underlying communication, disclosure and sharing. The communicator is not aware of the connection between one's beliefs and one's style of communication and there is no reason to assume that he or she try to adapt their communication style to their beliefs. The impact of the beliefs on the communication style is neither conscious not under the communicators' voluntary control.

Another conclusion of the findings is that each communicator disposes of the two studied communication styles. The activation of one or another is determined among other factors by one's $\mathrm{CO}$ motivation supporting one or another of the communication styles. Hence, if one desired to affect the activation of these communications styles the recommended way is by enriching or enhancing the meanings underlying these styles. This procedure is likely to be much more effective than training one or another of the communication styles.

It may be assumed that the same conclusions apply also to other communication styles in which one may be interested. The recommended procedure of affecting them is the indirect way of dealing with their underlying meanings which is likely to be more effective in regard to most behaviors than reinforcing directly the behaviors themselves.

\section{References}

Almushayqih, H. (2020). The role of the addressee and gender diversity in greeting behavior in the Saudi context. English Language Teaching, 13(6), 1.

Barnlund, D. C. (2008). A transactional model of communication. In. C. D. Mortensen (Eds.), Communication theory (2nd ed., pp. 47-57). New Brunswick, New Jersey: Transaction.

Kreitler \& T. Urbanek (Eds.) Conceptions of meaning (pp. 3-32). Hauppauge, NY: Nova Publishers.

Kreitler, H., \& Kreitler, S. (1982). The theory of cognitive orientation: Widening the scope of behavior prediction. In B. Maher \& W. B. Maher (Eds.), Progress in Experimental Pesonality Research (Vol. 11, pp. 101-169). New York: Academic Press.

Kreitler, S. \& Kreitler, H. (1990). The cognitive foundations of personality traits. New York: Plenum.

Kreitler, S. (2004). The cognitive guidance of behavior. In J.T. Jost, M. R. Banaji, \& D. A. Prentice (Eds.), Perspectivism in social psychology: The Yin and Yang of scientific progress (pp. 113-126). Washington, DC: American Psychological Association.

Kreitler, S. (2014a). Meaning and its manifestations: The Meaning System. In S.

Kreitler, S. (2014b). Changing attitudes and beliefs. In C. Pracana (Ed.), International psychological applications conference and trends (InPact) (pp. 99-102). World Institute for Advanced Research and Science (WIARS). Lisbon: Portugal. 
Kreitler, S. (2021). The construct of meaning. New York: Cambridge University Press.

Kreitler, S., Schwartz, R., \& Kreitler, H. (1987). The cognitive orientation of expressive communicability in schizophrenics and normals. Journal of Communication Disorders, 20, 73-91.

Kuria, G. N. 2019). Literature review: Leder communication styles and work outcomes. International Journal of Scientific and Engineering Research, 10(1), 1956-1965.

Littlejohn, S. W., Foss, K. A., \& Oetzel, J. G. (2021). Theories of human communication (11th ed.). Belmont, CA: Wadsworth Publishing.

Wang, R., Roy, A. R. K., Gorman, K. R., \& Ferguson, K. (2018). Attachment, relationship communication style and the use of jealousy induction techniques in romantic relationships.Personality and Individual Differences, 129, 6-11. 